\title{
A study of school bag weight and back pain among intermediate female students in Dammam City, Kingdom of Saudi Arabia
}

\author{
Rawan Saleem Alghamdi ${ }^{1}$, Hoda Mohamed Nafee*1,2, Awatef El-Sayed ${ }^{1}$, Saad Mohamed Alsaadi ${ }^{3}$ \\ ${ }^{1}$ College of Nursing, Imam Abdulrahman Bin Faisal University, Kingdom of Saudi Arabia \\ ${ }^{2}$ College of Nursing, El-Mansoura University, Egypt \\ ${ }^{3}$ College of Applied Medical Sciences, Imam Abdulrahman Bin Faisal University, Kingdom of Saudi Arabia
}

Received: May 26, 2018

DOI: $10.5430 /$ jnep.v8n12p105
Accepted: July 30, 2018

Online Published: August 22, 2018

\begin{abstract}
Background: The most common cause of low back pain in children is muscle sprain and strain which can occur from carrying a heavy backpack or from activities. This study aimed to assess the relationship between school bag weight and back pain among female students in Dammam city.

Methods: A total of 300 female students were included in this study both from east and west sectors of Dammam city, Saudi Arabia. Tools: Data were collected using (1) A structured questionnaire sheet including, socio-demographic data of the students, and close-ended questions about the school-bags as methods of carrying, (2) A weight scale that measured student's body weight and weight of the school bags, (3) A self-report (Numeric pain rating scale) that assessed pain intensity. Univariate and Multivariate Statistical analysis was performed to test the relationship between the study variables.

Results: A total of 288 school children (96.2\% out of 300) were carrying bags of weight more than $15 \%$ of their body weight. Shoulder and neck pain were reported by $40 \%$ of the female students. Statistically there is a significant relationship was found between school bags weight and severity of shoulder pain $(p=.042)$.

Conclusion and recommendation: The weights of schoolbags of Dammam city intermediate female students were higher than the internationally acceptable standards. Ministry of Education should set standards to prevent and mange problems of carrying heavy school bags in the intermediate school.
\end{abstract}

Key Words: Student, School bag, Musculoskeletal pain, Pain intensity

\section{INTRODUCTION}

Female students in intermediate schools participated $4.5 \%$ from total population in Dammam city in year of 2016, those female students carrying their school bags 5 days per week for the entire school year and the bags filled with heavy books, laptops, sports kit and packed lunches. Several health problems of the musculoskeletal system facing the children's body frames when they are carrying a heavy school bag. Because the musculoskeletal system of early adolescent children still on growing, the school bags weight and the undesirable consequences of heavy burden may possibly cause a permanent injury to the spine ${ }^{[1,2]}$ Epidemiological data that collected during the past 20 years proposed that most neck and back pain in children is of non-specific cause and not

\footnotetext{
*Correspondence: Hoda Mohamed Nafee; Email: honafee68@ hotmail.com; Address: College of Nursing, Imam Abdulrahman Bin Faisal University, Kingdom of Saudi Arabia.
} 
associated to the pathologic state or deformity. ${ }^{[3]}$

The most common cause of low back pain in children is muscle sprain and strain. This can occur from carrying a heavy backpack or from activities. ${ }^{[4,5]}$ The International Chiropractic Pediatric Association (ICPA) ${ }^{[6]}$ suggested that the school bags should not exceed $15 \%$ of a child's body weight. The Carrying a heavy backpack with a weight exceeding $15 \%$ of the student body weight can lead to a change in posture resulting pain in the upper-, mid-back, neck and low back in addition to local effect as headaches, muscle weakness, tingling in the arms, and stooped posture. ${ }^{[7-9]}$ Female students tended to carry their school bags over than $10 \%$ of their body weight and have a greater pain of neck, shoulder, and back pain than boys though carrying the similar school bag's weight. ${ }^{[10,11]}$ There are highest percentages of growth rate among the ages of 10-12 for girls and 13-15 for boys and the secondary centers of ossification not fusing completely until the mid-twenties, which keep them at risky for musculoskeletal pain. ${ }^{[12]}$ Many factors exaggerating musculoskeletal pain as school bags type, technique of carrying, walking to school more than 30 minutes daily while misuse and incorrect postural habits can cause irreversible damage to the spine if practiced since childhood. ${ }^{[13-15]}$

Carrying heavy school bag may produce musculoskeletal pain, affect posture in adolescents by forward trunk flexion 2 $\mathrm{cm}$ and compressed the disc of lumber vertebra. ${ }^{[16,17]}$ Those health problems consuming more time and budget due to the need of medications and chiropractic care, limit school bags weight to be less than $15 \%$ from the students' body weight, indicates the school to do education program about the school bag by instructing the parents and their children about the criteria of the appropriate school bags thought pamphlets, sufficient lockers, fixed school schedules, regular asking the student about their back pain in relation to if the school bag causing fatigue or pain, periodical checking and assessing the students' back pain by the doctor or the school nurse are the methods that prevent and minimize the complication of musculoskeletal pain associated with a heavy school bags. ${ }^{[2,7,18]}$ So this study aimed to identify the relationship between school bag weight and the intermediate female student's back pain at Dammam city.

\section{SUBJECTS AND METHOD}

\subsection{Study design}

A cross sectional research design was used.

\subsection{Settings}

The study was conducted in 4 females governmental intermediate schools that were chosen on random basis represented the eastern and western sectors in Dammam city, King Saudi
Arabia.

\subsection{Subjects}

A total number of 300 students aged from 13 to 15 years chosen in a random basis using a stratifying random sampling technique.

\subsection{Inclusion and exclusion criteria}

A generally healthy students who are agreed to participate in the study were included, while students who are impotent to stand on the weighing scale, unable to carry school bag, having disabilities and health problems associated with pain were excluded from the study subjects.

\subsection{Tools}

Three tools were used to collect data:

Tool (1): A structural questionnaire sheet was developed by the researchers after reviewing of the related literatures including two parts: The first part was the socio-demographic data of the student as age, grade, and name of the school, residence, weight of the student and weight of the school bag while the second part handled information about school bags using close-ended questions about schoolbags as, types, methods and frequency of carrying, and their opinion about weight of their school bags.

Tool (2): A scale with weight detectors was used to measure student's body weight, and weight of the school bag.

Tool (3): Self-report (Numeric pain rating scale) to assess the intensity of pain that encountered by the students. ${ }^{[19]}$

\subsection{Method of data collection}

(1) Ethical approval was asserted from the ethical committee in the University of Dammam (Institutional Review Board IRB \# 044), and Ministry of Education. In addition a written consent was obtained from each female student who participated in the study.

(2) Content validity of the tools was tested by five experts in the field.

(3) A pilot study was carried out on 10 students to evaluate the applicability and clarity of the tools and to estimate the length of the time needed to fill the sheet; participants were excluded from the total sample.

(4) The questionnaire was distributed between students during the activities hours, each class was separately, students were asked to answer questions individually after detailed explanation about the study objectives and procedure as well as statements would reassure that the information was confidentially and used only for the purpose of the research. 
(5) Explanation of the using of the numeric pain rating scale was done and students were asked to choose the appropriate number which is matched to pain intensity if, the number of zero on the scale means "no pain", 10 means "worst possible pain", from 2 to 3 was mild, while moderate from (4-6) and higher than 7 means severe pain.

(6) The weighing scale was located on a flat surface in a corner of the classroom and set to zero. Student asked to remove her shoes and weighting her when carrying the school bag first and for the second time without the bag, difference between the two measures was the weight of the bag. The school bag weight was considered appropriate load if ranged from $10 \%-15 \%$ of the student's body weight, while heavy load was exceeded than $15 \%$.

\section{Results}

Table 1 shows percentages of socio-demographic characteristics of students participated in the study. It shows that the age of students was ranged from 13 to 15 years and their grade level from 7 th to 9 th level. It notices equal percentages in a class venue which represented $34.4 \%$ for both the first and the second floor and $31.3 \%$ represented the third floor. In regard to students' health problems, it was observed that majority $(88.8 \%)$ of the studied students had no health problems, while $6.9 \%$ had asthma \& the rest of them $4.4 \%$ had anemia.

Table 1. Socio-demographic characteristics of students participated in the study

\begin{tabular}{lcl}
\hline Items & No $=\mathbf{1 6 0}$ & \% \\
\hline Age/Year & 55 & 34.4 \\
13- & 55 & 34.4 \\
$14-$ & 50 & 31.3 \\
15 & & \\
Grade Level & 55 & 34.4 \\
7th & 55 & 34.4 \\
8th & 50 & 31.3 \\
9th & & \\
Class Venue & 55 & 34.4 \\
First floor & 55 & 34.4 \\
Second floor & 50 & 31.3 \\
Third floor & & \\
Presence of health problems the students have & \\
No health problems & 142 & 88.8 \\
Asthma & 11 & 6.9 \\
Anemia & 7 & 4.4 \\
\hline
\end{tabular}

Table 2 illustrates the percentages distribution of students according to the characteristics of the school bags. As for the types of school bags, it was observed that on only one Published by Sciedu Press shoulder school bag was more prevalent among the studied students $68.8 \%, 29.4 \%$ of students were used both shoulder school bag and the rest of them $1.9 \%$ were used one hand type. The table also displays the percentage of the school bag weight to student's bodyweight, which the majority were $96.3 \%$ of students their school bags weight was more than $15 \%$ of their body weight. Only $0.6 \%$ of them their school bags weight was less than $10 \%$ of their body weight. Related to the causes of heavy school weight as responded by students, all students $100 \%$ stated that they have no lockers, $61.9 \%$ of them responded many books and $36.9 \%$ of them said uncoordinated schedules. Regarding the reaction of students related to heavy school bag, majority of students $89.4 \%$ stated that they sway left, right or bend forward, $4.4 \%$ of the of them their parents helped them in carrying the school bag and $23.8 \%$ of them responded that they take a rest while carrying the school bag. Majority of students $95.6 \%$ had no help in carrying the school bag. Nearly half of them $45.0 \%$ responded that they carrying bags thought the morning queue.

Table 2. Distribution of students according to the characteristics and the causes of the heavy school bags

\begin{tabular}{|c|c|c|}
\hline Items & $\mathbf{N}=\mathbf{3 0 0}$ & $\%$ \\
\hline \multicolumn{3}{|l|}{ Types of school bag } \\
\hline On one shoulder & 206 & 68.8 \\
\hline Both shoulders & 88 & 29.4 \\
\hline With one hand & 6 & 1.9 \\
\hline \multicolumn{3}{|c|}{ Percentage of school bag weight to student's body weight } \\
\hline Less than $10 \%$ & 2 & 0.6 \\
\hline $10 \%$ to $15 \%$ & 9 & 3.1 \\
\hline More than $15 \%$ & 289 & 96.3 \\
\hline \multicolumn{3}{|l|}{ Causes of heavy bag as responded by students } \\
\hline Many books & 186 & 61.9 \\
\hline Uncoordinated schedule & 111 & 36.9 \\
\hline Students have no lockers in the school & 300 & 100 \\
\hline \multicolumn{3}{|c|}{ Reaction of students related to heavy school bag** } \\
\hline Sway left, right, or bend forward & 268 & 89.4 \\
\hline Parents help in carrying the school bag & 13 & 4.4 \\
\hline Take a rest while carrying the school bag & 71 & 23.8 \\
\hline $\begin{array}{l}\text { Students have no help in carrying the school } \\
\text { bag }\end{array}$ & 287 & 95.6 \\
\hline $\begin{array}{l}\text { Students carrying their bag throughout the } \\
\text { morning Queue }\end{array}$ & 135 & 45.0 \\
\hline
\end{tabular}

Table 3 shows that the distribution of students according to the transportation methods and the time used to reach their schools. It was found that three quarters $75 \%$ of students are walking to school, $13.1 \%$ of student reach to school by bus while the rest of them $11.9 \%$ by special car. Table 3 also clarifies $96.7 \%$ of student take less than 10 minutes to reach 
their schools while $2.5 \%$ take $10-15$ minutes to reach their schools.

Table 3. Distribution of students according to the transportation methods and the time used to reach their schools

\begin{tabular}{lll}
\hline & $\mathbf{N}=\mathbf{3 0 0}$ & $\mathbf{\%}$ \\
\hline Method used to reach school & & \\
Walking & 225 & $75.0 \%$ \\
Special car & 36 & $11.9 \%$ \\
The bus & 39 & $13.1 \%$ \\
Time used to go to school walking & & \\
Less than 10 minutes & 218 & $72.5 \%$ \\
$10-15$ minutes & 7 & $2.5 \%$ \\
\hline
\end{tabular}

Figure 1 shows that $25.0 \%$ of the students had lower back pain, $40.0 \%$ of them complained shoulder pain while $31 \%$ had neck pain.

Figure 2 illustrates the distribution of students according to presence of pain due to carrying of the heavy school bag.
More than half $58.1 \%$ of students had moderate pain, while $37.5 \%$ had severe pain and few of them $4.4 \%$ had no pain.

Regarding the effect of pain on the student's daily life, Table 4 shows that $38 \%$ of students said that the pain not effect on their daily life, $32 \%$ of them had sleep disturbances from pain. As for student's reaction related to pain, $22.9 \%$ of them take medications without medical request, but $35.3 \%$ of them go to the physician, while $41.8 \%$ of them had no reaction to pain.

Table 5 demonstrates the relationship between the students' school bags weight and their musculoskeletal pain intensity. the table revealed that students whom their school bags weight more than $15 \%$ from their body weight suffering from ,moderate shoulder pain intensity $60.9 \%$ with statistically significant difference $(p=.042)$, moderate neck pain intensity constituted in $30.6 \%$, and sever was $30.6 \%$ of student with Statistically significant differences $(p=.024)$. More than half $57.5 \%$ of them had severe lower back pain intensity, while moderate pain intensity was reported by $40.0 \%$ of the students with no statistically significant difference $(p=.250)$.

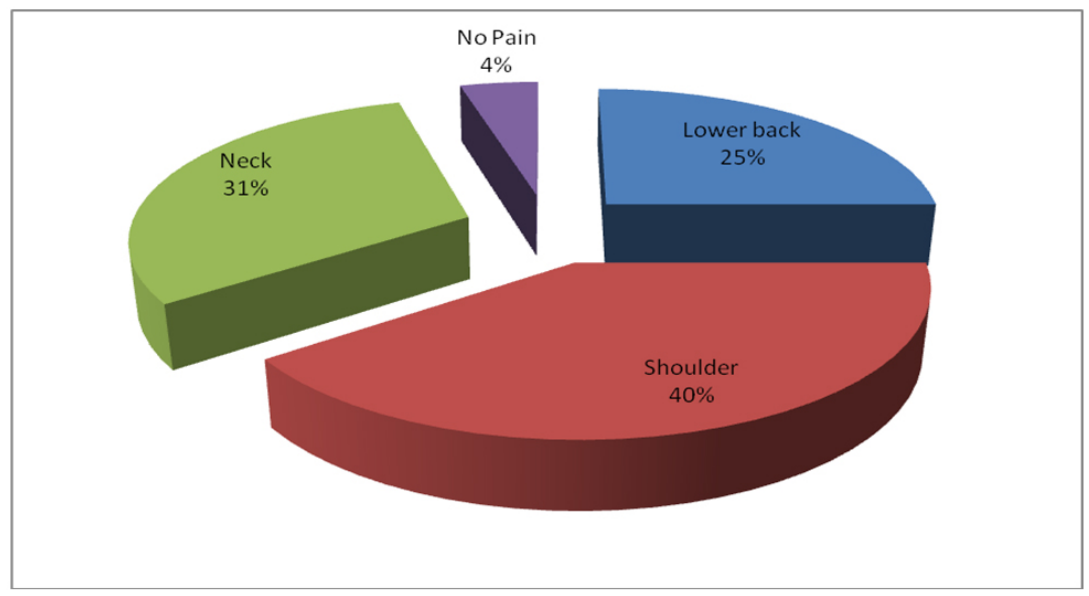

Figure 1. Distribution of students according to presence of pain

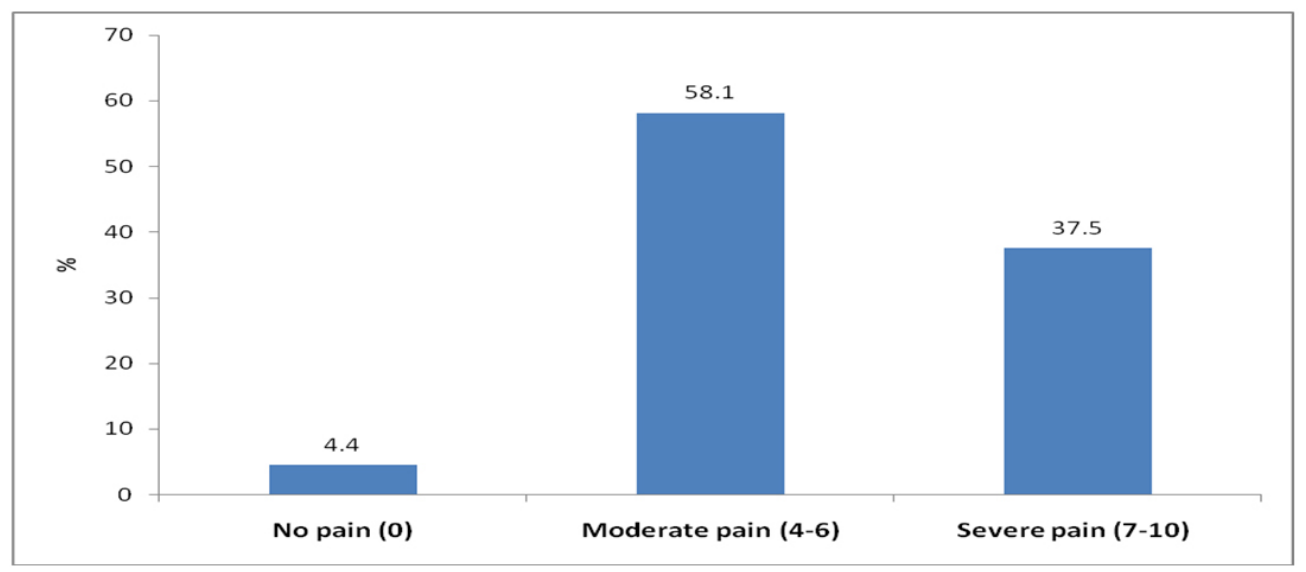

Figure 2. Distribution of students according to intensity of pain 
Table 4. Distribution of student's pain effect on their daily life and their reaction

\begin{tabular}{lll}
\hline & $\mathbf{N}=\mathbf{2 8 7}$ & $\mathbf{\%}$ \\
\hline Effect of pain in the daily life $(\mathbf{n}=\mathbf{1 5 3})$ & 109 & 38 \\
No effect & 7 & 2.6 \\
Can't get straight & 79 & 27.5 \\
Pain all day & 92 & 32 \\
Sleep disturbance & & \\
Students reaction related to pain & 101 & 35.3 \\
Go to the physician & 66 & 22.9 \\
Take medications without medical request (analgesics) & 120 & 41.8 \\
Have no reaction & & \\
\hline
\end{tabular}

Table 5. The relationship between the students' school bags weight and their musculoskeletal pain intensity

\begin{tabular}{|c|c|c|c|c|}
\hline \multirow{2}{*}{ Pain intensity } & \multirow[t]{2}{*}{ Bag weight } & \multicolumn{2}{|c|}{ Percentage of bag weight } & \multirow{2}{*}{$\begin{array}{l}\chi^{2} \text { Test } \\
p \text { Value }\end{array}$} \\
\hline & & $10 \%$ to $15 \%$ & More than $15 \%$ & \\
\hline \multicolumn{4}{|l|}{ Shoulder pain } & \multirow{3}{*}{$\begin{array}{l}\chi^{2}=2.271 \\
.042 *\end{array}$} \\
\hline Moderate & & $2(1.6 \%)$ & $73(60.9 \%)$ & \\
\hline Severe & & $2(1.6 \%)$ & $43(35.9 \%)$ & \\
\hline \multicolumn{4}{|l|}{ Neck Pain } & \multirow{3}{*}{$\begin{array}{l}\chi^{2}=0.945 \\
.024^{*}\end{array}$} \\
\hline Moderate & & 0 & $65(69.9 \%)$ & \\
\hline Severe & & 0 & $28(30.6 \%)$ & \\
\hline \multicolumn{4}{|l|}{ Lower back pain } & \multirow{3}{*}{$\begin{array}{l}\chi^{2}=1.388 \\
.250\end{array}$} \\
\hline Moderate & & $2(2.5 \%)$ & $30(40.0 \%)$ & \\
\hline Severe & & 0 & $43(57.5 \%)$ & \\
\hline
\end{tabular}

*Statistically significant differences

\section{Discussion}

Heavy school bags are one of the common factors that influence the incidence of musculoskeletal back pain and alteration of students' body posture. ${ }^{[20]}$ The musculoskeletal system react properly to compensate for this stress and alteration. A limit weight of school bags not excess $15 \%$ of the body weight is one of the methods that decrease and prevent students' back pain. ${ }^{[7]}$ So the researchers in this study assessed the relationship between heavy school bags and the intensity of back pain among intermediate school female's students.

The students' age ranged from 13 to 15 years and the majority $(96.3 \%)$ of them carried a heavy school bags where weighting more than $15 \%$ from their body weight and this finding is in agreement with those obtained by Matias et al. (2016), ${ }^{[21]}$ who found that $92.6 \%$ of participants are carrying a heavy school bags more than $15 \%$ of their body weight, while Paulaet et al. (2015) ${ }^{[11]}$ and Mwaka (2014) ${ }^{[22]}$ found that $(59.06 \%)$ and $(69.2 \%)$ of the students are carrying over $10 \%$ of their body weight. Regarding the pain intensity in relation to heavy school bags weight, the studied students complained from pain (30.6\%) in their neck (40\%) in their shoulders and $25 \%$ in their lower back (see Figure 1), this results are in the same lines of Haselgrove et al. $(2008)^{[15]}$ and Al-Saleem et al. (2016) ${ }^{[13]}$ who stated that neck, shoulders, upper and lower back pain is associated with carrying heavy loads as well as Rodríguez-Oviedo et al. $(2012)^{[14]}$ findings are agreed with results of the present study, where their findings revealed that $50 \%$ of participants had higher risk of back pain and $42 \%$ of them had back pathology due to carrying heavier backpacks.

The carrying method of bags is considered an important factor in back care, the right way of carrying a schoolbag can distribute the loads on the mussels and reduce the possibility of having back problems or back pain. On the other hand, uneven distribution of load on the back can cause muscle strain, back pain or deformation in back bones. Regarding types of school bags (see Table 3), above half of students (68.8\%) used a both shoulders school bags while $29.4 \%$ of them had a one shoulder school bag and the rest (1.9\%) had a one hand type but our study not handled the relation between types of school bags and students' back pain. Rebecca $(2015)^{[23]}$ found that the female students carried a loads in a two strapped rucksack more than $10 \%$ of their body weight could have back pain while those whom carried unilateral bag carriage are exposed to exaggerated shoulder pain, fu- 
ture research should be carried out to examine the anterior, posterior trunk muscles and leg muscles to investigate how the bag style affects those areas.

As for students' reactions to their heavy school bag (see Table 2), $89.4 \%$ of students stated that they are swaying left, right or bending forward and this results in harmony with Kistner et al. 2012 $2^{[24]}$ who displayed that wearing of school bags weighing more than $15 \%$ of the student's weight having an immediate significant change in Cranio vertebral Angle (CVA), from an increased position of their head forward.

Regarding occurrence of pain, the present study indicated that $35.3 \%$ of students visited the physician clinic, the similar result is seen in Panicker et al. in 2014 ${ }^{[26]}$ study mentioned that nearly $54 \%$ of the students diagnosed with myofascial pain and the rest with thoracic outlet disorders due to their heavy school bags.

The relation between the students' school bags' weight and their shoulder pain intensity (see Table 5) more than half of students $(60.9 \%)$ whose bag weight more than $15 \%$ of body weight had moderate shoulder pain, this result is agreed with those obtained by Panicker et al. in 2014, ${ }^{[25]}$ who stated that the majority of students had shoulder pain with signs of pressure over their shoulder. Moderate neck pain was constituted in $(69.9 \%)$ of students while severe pain was affected $30.6 \%$ of students whom carrying school bag weighting more than $15 \%$ from their body weight (see Table 5), this result is in the harmony with Kistener et al. (2012) ${ }^{[24]}$ who found a positive relation between heavy school bags and intensity of neck pain.

The current study did not find a relation between students' school bag's weight and their lower back pain intensity and this result disagreed with Farhood $(2013)^{[2]}$ who revealed that $(80.4 \%)$ of the students carrying schoolbags that weight more than $5 \mathrm{~kg}$ had lower back pain, additionally, Ibrahim $(2012)^{[26]}$ also found a strong correlation between school

\section{REFERENCES}

[1] Available from: https://www.moe.gov.sa/ar/Pages/Statis ticalinformation.aspx

[2] Farhood FH. Low back pain in schoolchildren: the role of school bag weight and carrying way. Journal of Natural Sciences Research. 2013; 3(8): 156-165.

[3] Mayank M, Upender S, Nishat Q. Effect of Backpack Loading on Cervical and Shoulder Posture in Indian School Children. Pediatric Review: International Journal of Pediatric Research. 2016; 3(6).

[4] Kovacs FM, Gestoso M, Gil del Real MT, et al. Risk factors for non-specific low back pain in schoolchildren and their parents: a bag's weight and the back pain. Finally, this study demonstrates that there is a relationship between heavy school bag weight and back pain and the school bag weight should not represented more than $15 \%$ of the students' body weight.

\section{Conclusion}

The majority of the female's students $(96.3 \%)$ their school bags weight were higher than the internationally standards which increase pain intensity in their shoulder, neck and lower back area. unavailability of lockers in their school, carrying many books in their bags and uncoordinated schedule were the most common causes of carrying a heavy school bags.

\subsection{Recommendations}

- Collaboration and integration between families, ministry of health and education to formulate and implement a plan about criteria of proper (school bags, carrying techniques bags weight) and prevention of students' health problems from carrying a heavy school bags.

- The schools should regulate the daily schedules and facilitates provision of lockers.

- Ministry of education should activate the idea of tablet use rather than of paper books in all schools.

- Further study to rollout deformities in skeletal system of students whom carrying school bags heavier than that stipulated in the international standards.

\subsection{Limitations of the study}

This study was limited in both genders, as it is conducted on girls only because the ministry of education refused presence of the female researchers in boys' schools as cultural constrictions.

\section{CONFlicts of InTERest Disclosure}

The authors declare that there is no conflict of interest. population based study. Pain. 2003; 103: 259-68. https ://doi .or g/10.1016/S0304-3959(02) 00454-2

[5] Pellisé F, Balagué F, Rajmil L, et al. Prevalence of low back pain and its effect on health-related quality of life in adolescents. Arch Pediatric Adolescent Med. 2009; 163: 658.

[6] American Chiropractic Association. Backpack Misuse Leads to Chronic Back Pain, Doctors of Chiropractic Say. Available from: http: //www . acatoday. org/content_css. cfm?CID $=65$

[7] Moore MJ, White GL, Moore DL. Association of relative backpack weight with reported pain, pain sites, medical utilization, and lost school time in children and adolescents. J. Sch Health. 2007: 
77(5): 232-239. PMid:17430435 https://doi .org/10.1111/j . 1746-1561.2007.00198.x

[8] Ingrid TS, Denise MM, Rodrigo GS, et al. Weight and mode of carrying schoolbags at elementary school: effect of the school grades and sex. J. Physiotherapy and Research. 2016; 23(2).

[9] Avantika R, Shalini A. Back problems due to heavy backpacks in school children. IOSR Journal of Humanities and Social Science. 2013; 10(6): 22-26. https://doi.org/10.9790/0837-1062226

[10] Dianat I, Javadivala Z, Asghari JM, et al. The use of schoolbags and musculoskeletal symptoms among primary school children: are the recommended weight limits adequate? Ergonomics. 2013; 56(1): 7989. PMid:23131119 https://doi.org/10.1080/00140139. 201 2.729612

[11] Paula AD, Silva J, Silva J. The Influence of Load Imposed by the Backpack School in Children and Teens in Brazil. Procedia Manufacturing. 2015; 3: 5350-5357. https://doi.org/10.1016/j.prom fg. 2015.07.645

[12] Macias BR, Murthy G, Chambers H, et al. Asymmetric loads and pain associated with backpack carrying by children. J. Pediatr Orthop. Jul-Aug 2008; 28(5): 512-517.

[13] Al-Saleem SA, Ali A, Ali SI, et al. A Study of School Bag Weight and Back Pain among Primary School Children in Al-Ahsa, Saudi Arabia. Epidemiology (sunnyvale). 2016; 6: 222.

[14] Rodrigues S, Montebelo MIL, Teodori RM. Plantar force distribution and pressure center oscillation in relation to the weight and positioning of school supplies and books in student's backpack. Rev Bras Fisioter. 2008; 12(1): 43-8.

[15] Haselgrove C, Straker L, Smith A, et al. Perceived school bag load, duration of carriage, and method of transport to school are associated with spinal pain in adolescents: an observational study. Australian Journal of Physiotherapy. 2008; 54(3): 193-200. https: //doi.org/10.1016/S0004-9514(08)70026-6

[16] Negrini S, Negrini A. Postural effects of symmetrical and asymmetrical loads on the spines of schoolchildren. Scoliosis. 2007; 2(8).
[17] Neuschwander TB, Cutrone J, Macias BR, et al. The Effect of Backpacks on the Lumbar Spine in Children. Spine. 2010; 35(1): 83-88. PMid:20023607 https://doi.org/10.1097/BRS.0b013e3181 b21a5d

[18] Gengler A. Relieve the Cost of Back Pain. Plan; Health and Wealth. Money. 2008.

[19] Wilson D, Hockenberry MJ. Wong's Clinical Manual of Pediatric Nursing. Seventh Edition, Mosby Elsevier. St. Louis Missouri. 2008.

[20] Spiteri K, Louisa M, Aquilina S, et al. Schoolbags and back pain in children between 8 and 13 years: a national study. Br J Pain. 2017 May; 11(2): 81-86.

[21] Matias N, Claudia T, Bruna N, et al. Back pain prevalence and associated factors in children and adolescents: An epidemiological population study. Rev. Saunde Rublica. 2016; 50: 31.

[22] Mwaka ES, Munabi IG, Buwembo W, et al. Musculoskeletal pain and school bag use: a cross-sectional study among Ugandan pupils. BMC Research Notes. 2014; 7(1): 222. PMid:24713177 https: //doi.org/10.1186/1756-0500-7-222

[23] Rebecca H, Rachel H, Joel H, et al. The Effects of Bag Style on Muscle Activity of the Trapezius, Erector Spinae and Latissimus Dorsi During Walking in Female University Students. Journal of Human Kinetics. 2015; 45: 39-47. PMid:25964808 https: //doi.org/10.1515/hukin-2015-0005

[24] Kistnera F, Fiebert I, Roach K. Effect of backpack load carriage on cervical posture in primary schoolchildren. Work. 2012; 41(1): 99-108. PMid:22246310

[25] Panicker R, Sandesh S. Prevalence of musculoskeletal pain in school going adolescents using school bags-A co-relational research. International Journal of Therapies and Rehabilitation Research. 2014; 3(4): 23. https://doi.org/10.5455/ijtrr. 00000039

[26] Ibrahim AH. Incidence of back pain in Egyptian school girls: Effect of school bag weight and carrying way. World Applied Sciences Journal. 2012; 17(11): 1526-1534. 